\title{
Peer Sexual Harassment in Zimbabwe State Universities: A Qualitative Exploratory Study
}

\author{
Daniel Mawere \\ Midlands State University, Gweru, Zimbabwe
}

\begin{abstract}
The study aimed at exploring and understanding undergraduate female students' experiences of sexual harassment by male peers on and around university campuses. The hegemonic masculinity perspective and the socio-cultural model combined to inform the study. The population of the study consisted of a purposive sample of 20 female undergraduate students in two state universities. Qualitative in-depth interviews were done to obtain understanding of how peer sexual harassment was experienced by undergraduate female students. Data was collected through one-on-one audio recorded semistructured interviews. Analysis of data was conducted using a narrative approach. Peer sexual harassment, perpetrated by male students, was a reality in the lives of female undergraduate students. Universities need to invest their efforts in addressing peer sexual harassment. Despite the fact that sexual harassment of female undergraduate students was taking place at the two state universities, victims seldom reported. Undergraduate female students need to be empowered to become more aware of the nature and extent of sexual harassment. $A$ decrease in peer sexual harassment incidences is realizable if universities improve aspects of their climate and culture. The is need for counselling of victims in order to mitigate the negative impact of peer sexual harassment.
\end{abstract}

Key terms: harassment, sexual harassment, female students, peers, sexual violence.

\section{INTRODUCTION}

Cexual harassment of female undergraduate students by male students has become a topical issue in the corridors of several university campuses worldwide. In these institutions, large numbers of young women come into contact with young men in both private and public settings and at various times within the campuses. These vast numbers of young adults live independently and in close proximity to each other for the first time (Miller,2018). Given the presence of sexual harassment in the corridors of these campuses, the campuses are no longer safe havens for most female students as they are exposed to this phenomenon on a regular basis. In other words the existence of sexual harassment in these institutions impacts negatively on the female undergraduate students' wellbeing and career development (Napolitano, 2015). Lack of understanding and awareness of what comprises sexual harassment makes the female undergraduate students easy targets of male sexual harassers.

Whilst peer sexual harassment is a common form of victimization among undergraduate students, its negative effects on female students' health and adjustment to university life have raised serious public concerns in recent years
(Chiodo, Wolfe, Crooks, Hughes, \& Jaffe. 2009) Empirical investigation on the issue remains relatively limited in number especially in African contexts. This study is likely to be among the first attempts to conduct a systematic inquiry of sexual harassment of female undergraduate students in Zimbabwe, especially as it relates to the harassment being perpetrated by male students.

Existing research on peer sexual harassment is largely based on North America and Western Europe (Dahlqvist, Landstedt, Young, \& Gadin, 2016). The issue receives significantly less recognition in African countries and Zimbabwe in particular. The study explores the sexual harassment experiences of undergraduate female students by boys in state universities in Zimbabwe to provide a more accurate picture while advancing current understanding of this significant gender issue. The aim of the study is to contribute to knowledge of peer sexual harassment behaviour in universities by providing an empirical basis for this form of sexual harassment as well as to promote awareness in the academic community about the seriousness of the problem in a Zimbabwean context.

\section{THEORETICAL FRAMEWORK}

The study utilizes the hegemonic masculinity perspective combined with the socio-cultural model as the theoretical framework for exploring peer sexual harassment of female undergraduate students by male students. The hegemonic masculinity perspective argues that sexual harassment is associated with reinforcing hegemonic and heterosexual masculinity and reinforcing asymmetrical power relations between the genders. Harassment is regarded as related to males' efforts to secure their manhood and content for peer status. Men perceive manhood as an impermanent state than womanhood, but they also endorse aggression as a means of providing or establishing threatened manhood (Messerschmidt, 2000; Weaver \& Bosson, 2010).

The issue of masculinity is particularly salient with regard to sexual harassment of females by males. A study of life histories of United States male offenders found out that the prevalent masculinity ideology requires young men to be aggressive, dominant, and tough and to depreciate efficiency, which increases their risk of committing harassment towards females. The studies showed that boys often use physical and verbal sexual harassment to highlight their power and superiority over female peers (Kimmel, 2008; Miller, 2018;). Such a climate, it should be noted, represents a general 
climate of male dominance and disrespect towards women in patriarchal societies.

The socio-cultural theory corroborates the hegemonic masculinity perspective as it examines the socio-political context in which sexual harassment is created and in which it takes place. The theory mainly focuses on norms, values and institutions that lead to sexual harassment. Sexual harassment, according to this theory is connected to the sexist ideology of male dominance and superiority referred to as patriarchy (Gutek, 1985; Stockdale, 1996; Thomas \& Kritzinger, 1997; Matchen \& DeSouza, 2000). This theory argues that the existing social system sees females as the inferior sex who must subject themselves to male dominance and superiority; sexual harassment is seen as a tool for maintaining this status. Harassment is viewed as the enforcement of gender role in equalities within the social system. In the case of the female student/male student relationship, inequality and male dominance is maintained by intimidating female students to yield to the demands of the perpetrator. Therefore, according to this theory, men believe that their behaviour is justified, whereas women blame themselves for being harassed.

Several risk factors of peer sexual harassment in the individual and personal level have been identified by the empirical literature which lands support to the discussion on masculinity dynamics. A major set of individual risk factors associated with peer victimization and harassment is antisocial behaviours. United States studies reveal that themes of aggression, power and rule- breaking are often emphasized in masculinity ideologies (Walters, 2001). On the interpersonal level, the risk to victims of peer sexual harassment often lies in the relationship problems between girls and boys, women and men.

Given that most societies are patriarchal in nature, patriarchy is the system that brings about and sustains the subordination and exploitation of women by men, be it in the home or in the university. Unequal power relations also contribute to subordination and exploitation of women.This comes about due to how males and females are socialised to fit into society. Men are expected to be aggressive and dominant, whereas women are expected to be passive and accepting. Males at the end of it all believe that their behaviours when they relate to and with women are justified. Women on the other end view themselves as an inferior sex and consequently blame themselves for being victims of sexual harassment perpetrated by men (Mackinnon, 1979; Vaux, 1993; Gruber \& Bjorn, 1996; Kalra and Bhugra, 2013).

In the context of this study, peer sexual harassment is a common experience among undergraduates but it is constantly under-studied compared to other types of peer harassment. Furthermore there is a lack of extensive research of the phenomenon in the African context. This study therefore hopes to bridge the knowledge gap in the existing literature and explore the potential risk factors of peer sexual harassment victimization among female undergraduates in the African context.

\section{Sexual harassment}

Sexual harassment in an educational context is defined generally as unwelcome requests or unacceptable conduct of a sexual nature that may interfere with a student's life and threaten their rights to education (Lichty, Torres, Valenti, \& Buchanan, 2008). Ladebo (2003), observes that sexual harassment is a critical stressor constituting a threat to academic performance of the individual. Furthermore, sexual harassment creates a hostile environment that undermines the educational mission of an institution. The phenomenon impacts a student's ability to participate in or to receive benefits, services or opportunities in the university programme. When students experience sexual harassment, the educational outcomes include declines in motivation to attend class, greater truancy, dropping classes, paying less attention in class, receiving lower grades, changing advisors, changing majors, and transferring to another educational institution or dropping out (National Academies of Sciences, Engineering and Medicine, 2018).

\section{Peer sexual harassment}

Peer sexual harassment, in the academic context, is a form of sexual attention that is unwanted or unwelcome to the target and that may produce an educational environment that is perceived as more negative and hostile (Chiodo, Wolfe, Crooks, Hughes, \& Jaffe, 2009). For the purpose of this study peer sexual harassment perpetrated by boys on girls will include unwanted or unwelcome behaviour, such as;

1. Making sexual comments, jokes, gestures or looks;

2. Showing sexual pictures, photographs, messages;

3. Touching or grabbing in a sexual way;

4. Forcing a kiss or forcing other unwelcome sexual behaviour;

5. Attempting to have or having unwanted sex with someone (Timmerman, 2005; Fineran \& Bolen, 2006;).

Peer sexual harassment is a gender issue and girls in particular are targeted by this behaviour. Gender, power and hierarchy fall broadly under social justice issues in which sexual harassment is viewed as sexual discrimination that affects women negatively. The existence of sexual harassment impacts negatively on female undergraduate students' wellbeing and career development. Peer sexual harassment victimization may cause a number of psychosocial and educational problems ranging from symptoms of anxiety and depression (Dahlqvist, Landstedt, Young, \& Gadin, 2016); self-harm and suicidal ideation (Chiodo, Wolfe, Crooks, Hughes, \& Jaffe, 2009); social violence; lower self-esteem( Duffy, Wareham, \& Walsh, 2004); and lower academic outcomes; lower self-esteem, poor physical and mental health (Gruber \& Fineran, 2008; Litchy \& Campbell, 2012). Consequently therefore, peer sexual harassment has a 
geometric multiplier effect on the victim through unavoidable constant social interaction (Kayuni, 2009).

A university environment is classified as hostile when the behaviour unreasonably interferes with a student's performance. A learning environment characterized by peer sexual environment is referred to as a hostile environment. A hostile learning environment is created when unwelcome harassment is severe or pervasive enough to alter the conditions of an individual's learning. Such an environment may create an abusive, intimidating and hostile learning environment (Tavares and Wodon, 2018). Universities also suffer when the campuses become known as unsafe for female students (Gouws and Kritzinger 2007). The need to foster a culture of respect, inclusion and civility in universities cannot be over emphasized.

\section{METHOD}

The study aimed at exploring and understanding undergraduate female students' experiences of sexual harassment by male peers on campus. A qualitative research approach was employed. The approach was selected given that it is mainly concerned with the role of interpretation. Interpretation as the core of qualitative research focuses on the meaning of human experience. Qualitative researchers are interested in understanding how people interpret their experiences, how they construct their worlds, and what meaning they attribute to their experiences (Merriam, 2009; Marshall \& Rossman, 2016). A qualitative research approach is a way of learning about social reality (Mason, 2018). The overall purpose of the study was to un derstand how undergraduate female students made sense of their lives and their experiences in an environment where sexual harassment was prevalent.

The target population for the study consisted of a purposive sample of 20 female undergraduate students from the two state universities. Female students who had experienced peer sexual harassment were purposively selected as participants to be interviewed. These students responded to the researcher's calls for those who had been subjected to peer sexual harassment by male counterparts at their universities. The calls were placed on the two universities' websites after being granted permission to do so by the universities management. The rationale for choosing female students subjected to sexual harassment was because these students were victims of sexual harassment. The purpose of the study and the use of the collected data were explained. In order to further comply with ethical requirements, the researcher sought informed consent from the participants before the interviews were carried out.

Qualitative in-depth interviews were carried out in order to obtain a better understanding of how peer sexual harassment is experienced by undergraduate female students. The interviews were conducted with a view to gathering the meaning they gave or extracted from sexual harassment experiences they had lived (Blinkmann, 2013). Given the sensitivity of the topic of study, the research participants' names and personal information was carefully treated and only used for the purpose of this article.

Data collection occurred on campuses in accessible lecture rooms and convenient offices where privacy was ensured. Data was collected mainly through one-on-one semistructured interviews. The interviews were audio recorded. All interviews were conducted by the same interviewer to minimize inter-researcher variability. Interviews were anonymized, transcribed and returned for analysis. All participants were undergraduate female students.

The analysis of data was conducted using a narrative approach. Through the analysis of the harassed female undergraduate students' narratives, the approach enabled the researcher to obtain a deeper and better understanding of the complexity of this human experience. Furthermore, it emphasized the importance of employing concrete examples of real facts, thereby building a space of confidence in which the story becomes the channel for the creation of awareness of the concrete reality (Elo, Karriainen, Kauste, Polkki, Utriainen, \& Kyngas,2014; Flick, 2014).

On ethical measures, permission was first of all obtained from two state universities to conduct the research on the basis of the submitted research outline and interview questions. Participants were briefed about the study. They were given the reassurance of confidentiality due to the sensitive nature of the study on sexual harassment. Consent was obtained from the female students before they were interviewed. All interviewed students provided written, informed consent to participate in the study. The main question that guided the study was: What are the peer sexual harassment experiences of female undergraduate students in Zimbabwe state universities?

\section{RESULTS}

\section{Peer sexual harassment experiences}

The purpose of the study was to find out the sexual harassment experiences of female students as victims and male students as perpetrators. Sexual harassment of female students by male students was taking place in both universities, the study found out. This was established in the interviews conducted in the two state universities. One university was identified as Western University (WU) and the other university was identified as Eastern University (EU). The participants were identified by a number. The findings narrated are in the excerpts that follow.

\section{Unwanted sex and or rape}

I gave my cell phone to my boyfriend who took it to his room outside the university. I followed the boy to his place to collect my cellphone. I found the boy outside his room talking to other boys. The two of us got into the boy's room to collect the cell phone. The boy closed the door and started to make advances to me. I resisted. I kicked, screamed and jumped hoping that the other boys outside would 
come to my rescue. However, the boy forced himself on me. I was raped (WU1),

I was given water by my boyfriend. When I drank the water I became confused only to wake up in the morning in my boyfriend's room outside the university campus. I had been sexually assaulted. I did not report. Only to be told by other girls, boys these days can put a drug, a sleeping tablet or a pill in your drink that makes you pass out or feel you want $\operatorname{sex}(E U 1)$.

I was given drugged ginger biscuits by a boyfriend. I ate these biscuits. I got intoxicated. I did not know what I was doing thereafter. Only to wake up realizing that I had been sexually abused by the boyfriend (WU2).

These female students had unwanted sex with boyfriends. The three excerpts above show how male students go to the extent of raping female students. For boys, having sex with a first year girl is viewed as a significant achievement one which they will tell their friends to boost their popularity. This is masculinity ideology at work. These three excerpts show the extreme cases of sexual abuse in the form of rape. Apparently none of them reported these incidents.

Being touched in an unwanted sexual way

There was a boy in my class who consistently touched me in a sexual way that I really did not appreciate. He would touch my buttocks and my breasts among other sensitive parts of my body. However, I never reported any of these incidents to anybody. I suffered in silence as I thought that nobody would take me seriously if I reported the harassment to them (EU2).

I faced an ongoing sexual harassment by a male classmate who continuously touched me inappropriately in class by way of groping my breasts, touching my buttocks, stroking my thighs and in-between my legs even when I told him to stop. I never bothered to report to the powers that be (WU3.

Some male student tried to force me to kiss him and pushed me into a lecture room where there were no people. However I managed to run away from him (EU3)

Unwanted, unwelcome and inappropriate touching of buttocks, breasts, thighs and in between the legs is physical sexual harassment. Unwelcome and unwanted kiss is again sexual harassment. The three excerpts above go to show how male students sexually harassed their female counterparts.

Sexual related comments
The two excerpts below go to show another way in which female undergraduate students have been subjected to harassment in form of sexually related comments.

I was walking alone on campus. As I passed through a group of male students, they started making sexual comments about my appearance. One of them remarked "You have very big breasts. One day I will suck them" (WU4)

I got whistled to by a number of male students on university grounds. Furthermore sexual related comments were made to me (EU4).

The female students interviewed were subjected to the above mentioned sexual comments. Verbal remarks of the above nature amount to verbal sexual harassment. Such sexist comments are meant to demean female undergraduate students. The comments impact negatively on the recipients.

Video recorded sexual encounters

The excerpts below reveal sexual encounters of lovers in which the boyfriends were aware that the encounters were being videotaped whilst their female lovers were not aware that the sexual encounters were being videotaped.

I was in love with a fourth year student when I was in first year. We had sexual intercourse. I was not aware that the encounter was being videotaped. When I wanted to discontinue the relationship I was threatened with disclosure of our sexual encounters. I thought it was a bluff. When the fourth year student graduated he posted the video on social media. (WU5)

I fell in love with a boy who had been at university for two years. We had intimate moments together. I was not aware that these moments were being captured by hidden cameras. When our relationship became untenable the video clip went viral. (EU5).

I was sent unwanted pornographic images through email by one of the male students I was doing the same degree programme with. (EU6)

The excerpts above go to show how female students are victims of sexual harassment that involves technology. In two of the excerpts above there seems to be a measure of consensus in having sexual intercourse. However the female students were not aware that the encounters were being videotaped. After falling in love with senior male students and agreeing to have sexual intercourse they are then held to ransom for subsequent sexual encounters through threats of exposing to the world the sexual acts through videos taken without their knowledge and consent.

In the third excerpt unwanted pornographic images were sent to her. Again technology was used to sexually harass the female student. 
Sexual harassment during and after welcome bashes

When I was in Year 1 Semester 1, I was invited to a party by a male Year 4 Semester 1 student. I was drugged by this student during the bash. I was then sexually abused and dumped by him. (EU7)

During the first week at the university there was a welcome bash. I was given a drugged cake by one of the boys who had been at the university for a longer time. I had not taken anything intoxicating before. I was then sexually abused. I do not know how many boys abused me. After this ordeal and in my stupor, I was taken to my room (WU6).

During orientation there was a bash. A boy who had been at the university for years bought me a drink as I danced. He spiked the drink with an intoxicating substance. I do not know what happened after as I woke up naked in the boy's room. I had been raped. I took my clothes and went to my hostel. I did not report this incident to anyone (WU7).

I got sexually assaulted by a male student after he had spiked my drink at a university party (EU8)

Spiked drinks and drugged cakes led to the sexual abuse of the female undergraduate students. The male students as sexual harassment perpetrators made the female student victims to consume spiked drinks and drugged cakes then sexually assault them in their intoxicated state. Drugging a female student prior to a sexual encounter and then dumping her amount to rape, the most extreme of sexual harassment.

Roommates and boys engaging in sexual intercourse in one's presence

I was sharing a room with a female colleague in a hall of residence at campus. A male partner, a boyfriend of my roommate visited her. I was in the room. The two started kissing each other and had sexual intercourse in my presence. It was late at night and I could not go anywhere (WU8)

A male student and a female student who were in love came into our female students' hostel room. We shared this room as four female students. On that occasion I was the only other person in the room. They started cuddling each other in my presence, kissing each other and had sexual intercourse in my presence as a roommate. They just used a curtain to prevent me from seeing what they were doing. I was reading and I stopped. I was disturbed. I complained and I was told that I was free to go to other hostels even though it was very late at night. I tried to report to the warden and I was told that I was overzealous. I tried to report to the sub-warden who was also doing it and the report did not go beyond her. The sub- warden was whiter than me. The roommate

thereafter hated me. (EU9)

For students to have sexual intercourse in the presence of a roommate is extremely inconsiderate and constitutes sexual harassment. The roommate's reading is disturbed. Efforts to report this behaviour were frustrated. At the same time her peace was interfered with.

The sexual harassment experiences emerging from the interviews presented above included: unwanted sexual intercourse or rape (WU1, WU2,EU1) ; being touched in an unwanted sexual way (EU2, EU3 and WU3); receiving sexually related comment(WU4 and EU4); video recorded sexual encounters (WU5, EU5 and EU6); sexual intercourse after taking spiked drinks and drugged cakes during and after welcome bashes(EU7, EU8, WU6 and WU7) and a roommate engaging in sexual intercourse with a boyfriend in the presence of a female roommate (WU8 and EU9).

The sexual harassment experiences of female undergraduate students in the two state universities were by and large similar as male students abused female students. This could be due to their societal perception as possessors of power. This is corroborated by empirical research arguing that males often use physical and verbal sexual harassment to highlight their power and superiority over female peers (Miller, 2018; Kimmel, 2008). Such a climate, it should be noted, represents a general climate of male dominance and disrespect towards women and girls in patriarchal societies.

\section{DISCUSSION}

What is evident from the incidences captured in this study is that sexual harassment and rape as well as unsolicited physical contacts and unwanted kisses are rife amongst students in the two state universities. For students to have sexual intercourse in the presence of a roommate is inconsiderate and constitutes a form of sexual harassment. Videotaping a sexual encounter without the consent of the female partner is unacceptable. Welcome bashes that lead to female students being sexually harassed by male students after they have been given spiked drinks and drugged biscuits amount to rape. Peer sexual harassment as it obtains in the two state universities is associated with reinforcing hegemonic and heterosexual masculinity and reinforcing asymmetrical power relations between boys and girls. This confirms findings elsewhere that state that peer harassment is related to males' efforts to secure their manhood and content for peer status as well as the perception that manhood is an impermanent state than womanhood. Aggression is endorsed as a means of providing or establishing threatened manhood as argued by Messerschmidt (2000) and Weaver \& Bosson (2010). For the boys, having sex with a first year girl is viewed as a significant achievement one which they will tell their friends to boost their popularity. This is masculinity ideology at work.

It is apparent from this study that sexual harassment is a problem at the two state universities, thereby strengthens the 
argument that sexual harassment of female undergraduate students by male students remains a problem for undergraduates in Zimbabwe. Hence Ladebo (2003) stresses that sexual harassment has been recognized as a critical stressor that constitutes a threat to the task performance of the individual and even the organisational outcome. Whilst incidences of harassment cannot be quantified the bottom line is that the phenomenon obtains in the two state universities. The existence of peer sexual harassment in the two universities therefore suggests a student culture that accepts and tolerate this type of behaviour. The institutions also suffer when the campuses become known as unsafe for female students (Gouws and Kritzinger 2007).

Quite a number of female students did not report the incidences of sexual harassment they experienced. Fear appears to militate against them reporting. They are afraid to report sexual harassment to the relevant university structures because of negative consequences that might befall them. There seems to be reluctance to report such problems even to the Student Representative Council. This might be as a result of the fact that the structure is managed by male peers. Furthermore the structure might be viewed as powerless in view of the seriousness of the case. Female students seem to doubt the effectiveness of structures set up to assist them because they are apprehensive about the outcome if they report the harasser to such structures. Given indications that female students fear to report sexual harassment perpetrated by male students, it can be concluded that there is underreporting of sexual harassment in the two state universities (Mitchell, Jones, Shattuck \& Wolak, 2016).

The behaviour of male students as pointed out by the female victims appear to confirm the socio-cultural theory position that societal norms, values and institutions lead to sexual harassment given the sexist ideology of male dominance and superiority characterizing patriarchy (Gutek, 1985; Stockdale, 1993; Thomas \& Kritzinger, 1997; Matchen \& DeSouza, 2000). Furthermore, given that the Zimbabwean society is patriarchal in nature, patriarchy therefore is the system that brings about and sustains the subordination and exploitation of female students by male students in the university. This comes about due to how boys and girls are socialised to fit into society. Men and boys are expected to be aggressive and dominant, women and girls on the other hand are expected to be passive and accepting (Gruber \& Bjorn, 1986). Boys at the end of it all believe that their behaviours when they relate to and with girls are justified. Girls on the other end view themselves as an inferior sex and consequently blame themselves for being victims of sexual harassment perpetrated by boys (Mackinnon, 1979; Vaux, 1993).

Female undergraduate students in Zimbabwe state universities are exposed to a wide variety of inappropriate and or unacceptable behaviours of a sexual nature that infringes their right to a respectful and safe learning environment as well as their dignity. Greater efforts are needed to analyse and prevent peer sexual harassment in state universities. Peer sexual harassment has great potential of creating a very hostile environment for the harassed female student to the extent that she can seriously be affected academically as well as socially. A danger with this form of harassment is that the interaction amongst peers is very high. The peer sexual harassment has a geometric multiplier effect on the female victims through unavoidable constant social interaction (Kayuni, 2009).

It should be pointed out that physical and personal safety; dignity and well-being of female students are of critical importance to the university just as intellectual property and research facilities are. The protection of female students from sexual harassment requires a robust, open and consistent discussion as is accorded to ethics and plagiarism in a university environment. Orientation and initiation activities of female students are favoured moments for prevention and awareness-raising. However, some of the activities that take place during these initiations can be disrespectful and incite sexually inappropriate behaviour. Female students who are beginning university are notably more vulnerable, given their status, their limited experience and the challenges of adapting to a new student life. Cases of inappropriate sexually suggestive behaviour during initiation are high. Research shows that first-year female students are at higher risk of sexual harassment in their first eight weeks at the university (Ontario Women's Directorate, 2013).

Institutional support for addressing peer sexual harassment issues has not been forthcoming given that universities are more concerned about protecting their public image and generally do not want publicity around sexual harassment (Bennett, 2005). Whilst the university risks reputational consequences, it also risks loss of trust by its undergraduate female students. The institution also suffers when the campus becomes known as unsafe for female students (Gouws \& Kritzinger 2007, 71). Universities are expected to keep the students they serve safe and promote an effective learning environment. Universities are charged with significant responsibility to remedy sexual harassment on campus (Dunn, 2014; Napolitano, 2015).

\section{RECOMMENDATIONS}

Peer sexual harassment is a reality in the lives of many female undergraduate students. It is hoped that the results of this study have contributed to a more precise knowledge of the nature and context of sexual harassment of female undergraduate students. Sexual harassment of female students as revealed in this study mirrors a gendered hierarchal society. In the circumstances the need for education and training encouraging a more equal and egalitarian environment cannot be overemphasized.

1. Universities in which peer sexual harassment obtains are undermining the experience the institution endeavours to provide to its students. Sexual harassment incidents are a sharp contrast to the mission of university education. Universities need to 
fight against sexual harassment in order to contribute to a better society.

2. Given that this study focused on sexual harassment experiences of female students, future research should include the perceptions of male students towards peer sexual harassment as a way to search for possible similarities and discrepancies with female student experiences.

3. Universities should build a culture of respect and respond appropriately by supporting female victims of sexual harassment as well as sanctioning male student perpetrators. Fostering a positive climate remains the primary approach to reducing sexual harassment of female students by male students through implementation of programmes that foster trust and respect among all students.

4. The negative impact of sexual harassment perpetrated on female students by male students, calls for the need for a counselling programme characterized by energy and vigour in universities. Such a counselling programme would go a long way in stemming down the incidences of peer sexual harassment targeted at both victims and perpetrators of peer harassment.

5. The study focused on sexual harassment experiences of female students, however a more comprehensive understanding of sexual harassment of students in a university environment could not have come out clearly. Selective participation could have biased the findings. A global view of sexual harassment in universities that takes on board the whole university community would contribute to a comprehensive and sufficient understanding of the phenomenon.

\section{LIMITATIONS}

This study has its own limitations. Participants were from two state universities' settings, therefore the study was limited by the inability to inquire about sexual harassment experiences of female students from across different universities. Future research could benefit from a more rigorous recruitment method to yield a larger sample. Therefore findings may not apply across all settings in universities.

Furthermore the 20 participants self-selected to participate in the study. Therefore the sample and findings could be biased toward individuals who felt strongly about their experiences when there could have been other students with varied experiences on the same phenomenon.

Despite these limitations, the study's conclusion is that female students do experience sexual harassment perpetrated by male students in state universities. Peer sexual harassment negatively affects victims in the sense that such an institutional environment impacts negatively on the learning and social living of the victims.

\section{REFERENCES}

[1] Bennett, J. (ed.) (2005). Killing a virus with stones, Cape Town: African Gender Institute.

[2] Blinkmann, S., (2013). Qualitative Interviewing. Oxford: Oxford University Press.

[3] Chiodo, D., Wolfe, D. A., Crooks, C., Hughes, R., \& Jaffe, P. (2009). Impact of sexual harassment victimization by peers on subsequent adolescent victimization and adjustment: A longitudinal study. Journal of Adolescent Health, 45, 246-252. doi:10.1016/j. jadohealth.2009.01.006.

[4] Dahlqvist HZ, Landstedt E, Young R, Gadin KG (2016). Dimensions of peer sexual harassment victimization and depressive symptoms in adolescence: a longitudinal cross-lagged study in a Swedish sample. Journal of Youth Adolescence. https://doi.org/10.1007/ s10964-016-0446-x

[5] Duffy, J., Wareham, S., \& Walsh, M. (2004). Psychological consequences for high school students of having been sexually harassed. Sex Roles, 50, 811-821. doi:10.1023/B:SERS.00000 29099.38912.28.

[6] Dunn, L. (2014). Addressing sexual violence in higher education: Ensuring compliance with the Clery Act, Title IX and VAWA. The Georgetown Journal of Gender and the Law, 563- 584

[7] Elo, S. Karriainen, M. Kauste, O., Polkki, T. Utriainen, K. \& Kyngas, H. (2014).Qualitative Content Analysis: A focus on Trustworthiness. SAGE Open 4 (1). (1-10)

[8] Fineran, S., \& Bolen, R. (2006). Risk factors for peer sexual harassment in schools. Journal of Interpersonal Violence, 21, 1169-1190. Doi : 10.1177/0886260506290422.

[9] Flick, U. (2014). The Sage handbook of data analysis. London: Sage Publication Ltd.

[10] Gouws, A \& Kritzinger, A. (2007) Dealing with sexual harassment at institutions of higher learning: Policy implementation at a South African university. South African Journal of Higher Education, 21(1), 68-84

[11] Gruber J.E. \& Bjorn, L. (1996). Blue-collar blues: the sexual harassment of women autoworkers, Work and Occupations, 9, 271-298.

[12] Gruber, J., \& Fineran, S. (2008). Comparing the impact of bullying and sexual harassment victimization on the mental and physical health of adolescents. Sex Roles, 59, 1-13. Doi:10.1007/s11199-008-9431-5

[13] Gutek, B.A. (1985). Sex and the workplace. San Francisco, Jossey-Bass.

[14] Kaln, G. \& Bhugra, D (2013). Sexual Violence against Women. Indian Journal of Psychiatry. 55(3) 244-249.

[15] Kayuni, H.M. (2009). The challenge of studying sexual harassment in higher education: an experience from the University of Malawi's Chancellor College Journal of International Women's Studies, 11, (2), 83.

[16] Kimmel, M. (2008). The gendered society (3rd ed.). New York, NY: Oxford University Press.

[17] Ladebo, O. J. (2003). Sexual Harassment in Academia in Nigeria: How real? African Sociological Review, 7(1), 117-161

[18] Ladebo, O. J. and J. O. Shopedu. 2004. Sexual harassment: Perceptions and coping strategies among undergraduate students in Nigeria. University of Agriculture. Acta Academic 36(3): 223238.

[19] Lichty, L., Torres, J., Valenti, M., \& Buchanan, N. (2008). Sexual harassment policies in k-12 schools: Examining accessibility to students and content. Journal of School Health, 78, 607-614. doi:10.1111/j.1746-1561.2008.00353.x

[20] Lichty, L. F., \& Campbell, R. (2012). Targets and witnesses: Middle school students' sexual harassment experiences. Journal of Early Adolescence, 32(3), 414-430. [Crossref], [Web of Science ®], [Google Scholar]

[21] Mackinon, C. (1979). The Sexual Harassment of Working Women, New Haven, CT: Yale University Press.

[22] Marshall, C., \& Rossman, G. (2016). Designing qualitative research. Thousand Oaks, CA: Sage.

[23] Mason, J. (2018). Qualitative Researching London, Sage. 
[24] Matchen, J. \& DeSouza, E. (2000). The sexual harassment of faculty members by students. Sex Roles, 42, $295-306$.

[25] Merriam, S.B. (2009). Qualitative Research: A guide to design and implementation: San Francisco; John Wiley and Sons.

[26] Ontario Women's Directorate, (2013). Developing a Response to Sexual Violence: A Resource Guide for Ontario's Colleges and Universities.

Available

at: http://www.citizenship.gov.on.ca/owd/english/endingviolence/campus guide.shtml

[27] Messerschmidt, J. W. (2000). Becoming 'real men': Adolescent masculinity challenges and sexual violence. Men and Masculinities, 2, 286-307. doi:10.1177/1097184X00002003003

[28] Miller, E. (2018). Reclaiming gender and power in sexual violence prevention in adolescence. In PubMed doi. $1177 / 10 / 1077801217753323$

[29] Mitchell, K. J., Jones, L. M., Turner, H. A., Shattuck, A., Wolak, J. (2016). The role of technology in peer harassment: Does it amplify harm for youth? Psychology of Violence, 6, 193-204. doi:10.1037/a0039317 Google Scholar | Crossref | ISI

[30] Napolitano, J. (2015). Only yes means yes: An essay on university policies regarding sexual violence and sexual assault. Yale Law \& Policy Review, 387-402.

[31] National Academies of Sciences, Engineering, and Medicine. (2018). Sexual Harassment of Women: Climate, Culture, and Consequences in Academic Sciences, Engineering, and Medicine. Washington, DC: The National Academies Press. https://doi.org/10.17226/24994.

[32] Ontario Women's Directorate, (2013). Developing a Response to Sexual Violence: A Resource Guide for Ontario's Colleges and Universities.

Available http://www.citizenship.gov.on.ca/owd/english/endingviolence/campus_guide.shtml
[33] Stockdale, M.S. (1996). The role of sexual misperceptions of women's friendliness in an emerging theory of sexual harassment. Journal of Vocational Behaviour, 42, 84-101.

[34] Tavares, P. \& Wodon, Q. (2018). Ending Violence against Women and Girls. Global and Regional Trends in Women's Legal Protection against Domestic Violence and Sexual

Harassment. Washington D.C.: The World Bank. [Google Scholar]

[35] Thomas, A. (1997). Men behaving badly? A psychosocial exploration of the cultural context of sexual harassment. In Thomas, A. and Kritzinger, C. (eds), Sexual Harassment: Contemporary Feminist Perspectives. Buckingham: Open University Press.

[36] Timmerman, G. (2005). A comparison between girls' and boys' experiences of unwanted sexual behaviour in secondary schools. Educational Research, 47, 291-306. doi:10.1080/ 00131880500287641.

[37] Vaux, A. (1993). Paradigmatic assumptions in sexual harassment research: Being guided without being led. Journal of Vocational Behaviour, 42, 116-135.

[38] Walters, G. D. (2001). The relationship between masculinity, feminin-ity, and criminal thinking in male and female offenders.SexRoles, 45, 677-689. doi:10.1023/A:1014819926761. (1) (PDF) Factors Associated with Peer Sexual Harassment Victimization Among Taiwanese Adolescents. Available from: https://www.researchgate.net/publication/235898126 Factors Ass ociated with Peer Sexual Harassment Victimization Among T aiwanese Adolescents [accessed Aug 09 2021].

[39] Weaver, J.R. \& Bossom, J. (2009). The proof is in the punch: Gender differences in perceptions of action and aggression as components of manhood In Sex Roles doi.10.1007/511199-9713-6 